\title{
Low-frequency Raman spectrum of crystalline 2-(2'-hydroxyphenyl)benzoxazole and density-functional based tight-binding phonon calculations
}

\author{
Syetov Y. \\ Department of Solid State Physics and Optoelectronics, \\ O. Honchar Dnipropetrovsk National University, 72 Gagarin Ave., 49010 Dnipro, \\ Ukraine, e-mail:setov2003@yahoo.com
}

Received: 02.12 .2016

\begin{abstract}
Unpolarized Raman spectrum of crystalline 2-(2'-hydroxyphenyl) benzoxazole in the region $15-350 \mathrm{~cm}^{-1}$ is compared with the results of densityfunctional based tight-binding lattice vibration calculations and oriented gas model. The Raman bands observed in the region $25-95 \mathrm{~cm}^{-1}$ are assigned to vibrations that are mainly external; the bands with the frequencies above $150 \mathrm{~cm}^{-1}$ are attributed to internal vibrations. It is demonstrated that the molecular in-plane bending vibration, which changes the distance between the oxygen and nitrogen atoms constituting a proton-transfer site, undergoes splitting and mixing with the out-of-plane and external vibrations, giving rise to the Raman bands observed at 115 and $140 \mathrm{~cm}^{-1}$.
\end{abstract}

Keywords: phonons, molecular crystals, Raman spectra, density-functional based tight-binding method, oriented gas model

PACS: $78.30 . \mathrm{Jw}, 63.20 .-\mathrm{e}$

UDC: $538.91,538.958,543.42$

\section{Introduction}

A phenomenon of photoinduced excited-state intramolecular proton transfer has been attracting much attention of researchers for several decades as an ultrafast photochemical reaction and a process that could have many potential applications, e.g. when tailoring laser dyes and electroluminescent materials [1]. As an example, a photoreactive compound based on excited-state intramolecular proton transfer in a crystalline state has been probed as a possible lasing material [2]. Low-frequency intramolecular vibrations have been considered to play a prominent role in the proton transfer process, changing the distance between a proton donor and an acceptor [3]. In molecular crystals, intermolecular forces give rise to the vibrational motions corresponding to translational and rotational degrees of freedom of molecules. The frequencies of these external vibrations are usually located in the range $0-150 \mathrm{~cm}^{-1}$ and, moreover, new lattice modes treated as a result of mixed internal and external vibrations could appear [4].

According to the X-ray data [5], the crystal lattice of 2-(2'-hydroxyphenyl)benzoxazole (HBO) is orthorhombic $\left(\mathrm{Pna}_{1}\right.$ ), with four molecules per unit cell (see Fig. 1). The adjacent molecules are stacked into chains with interplanar distances $3.58 \AA$. A high concentration of $\mathrm{OH} . . . \mathrm{O}$ rotamers, which corresponds approximately to the ratio $1: 1$, has been determined by the $\mathrm{X}$-ray data for HBO [5]. However, only the fluorescence band associated with tautomer has been found in crystalline HBO [6]. A study of the infrared spectra of $\mathrm{HBO}$ in the region of intramolecular vibrations has not revealed the bands that can be assigned to the vibrations of $\mathrm{OH} . . . \mathrm{O}$ rotamers, thus pointing to a low number of this species [7]. 


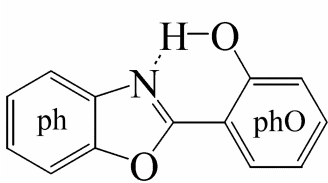

a)

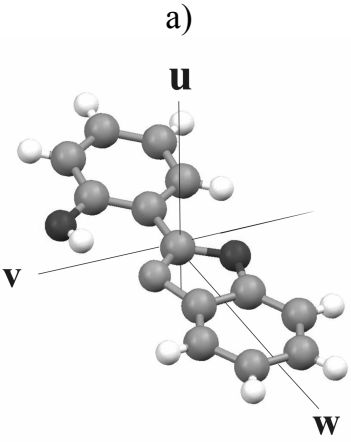

c)

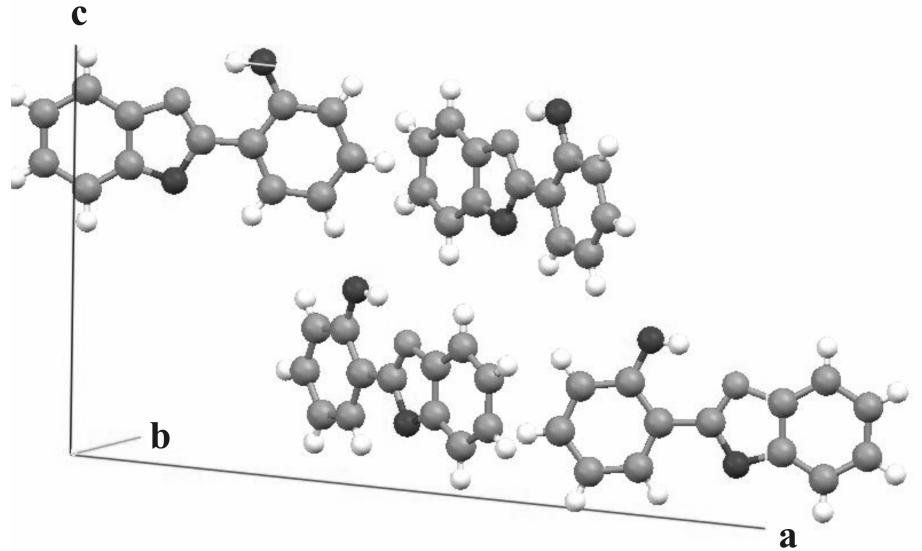

b)

Fig. 1. Structural formula of HBO molecule (a), crystal lattice cell of HBO [5] (b), and principal axes of inertia of the molecule (c).

The aim of the present work is to elucidate the influence of intermolecular forces on the lowfrequency vibrational spectrum of $\mathrm{HBO}$ in its crystalline state.

\section{Experimental and computational details}

Unpolarized Raman spectrum has been measured at the room temperature in a standard backscattering $\left(135^{\circ}\right)$ geometry, under excitation $(532 \mathrm{~nm})$ with the second harmonic of a Q-switched YAG: $\mathrm{Nd}^{3+}$ laser LTI-701 that operates at the average power $200 \mathrm{~mW}$. An unpolished single crystal of HBO with the dimensions of $2.0 \times 1.0 \times 0.5 \mathrm{~mm}^{3}$ is used in our experiments. The spectra have been recorded with a double monochromator DFS-12 equipped with a photomultiplier FEU-79. The spectral resolution is equal to $4 \mathrm{~cm}^{-1}$.

The vibrational modes of HBO crystals have been calculated with a known density-functional based tight-binding method (DFTB), with a third-order correction and a van der Waals interaction correction implemented within a DFTB + program package $[8,9]$. The latter correction was performed using a Lennard-Jones potential with UFF parameters [10]. A $3 \times 3 \times 3$ supercell folding has been employed for the Brillouin zone sampling. The phonon calculations have been performed with taking no rotameric disorder into account for the Brillouin zone centre under quasi-harmonic approximation that assumes the cell parameters fixed at the values taken from the X-ray data [5]. The vibrations of the isolated molecule have been calculated in the harmonic approximation. The intensities of the Raman lines have been evaluated within the oriented gas model, using the polarizability and derivatives of the polarizability obtained by density functional theory (DFT) calculations for the isolated molecule. The DFT calculations have been performed basing on a GAMESS program suit $[11,12]$ and using a B3LYP functional and 6-31G(d,p) basis set.

The motion of a molecule under crystal lattice vibrations can be approximately considered as a translation of its mass centre, a rotation (or libration) and internal vibrations, so that the internal vibrations should satisfy the Eckart conditions [4]. New generalized coordinates for the displacement of molecule $k$ are the centre of mass translation $t_{\alpha}^{k}$, the angles of rotation about the principal inertia axes $\theta_{\beta}^{k}$ and the internal coordinates $q_{\mu i n}^{k}(\mu=1 \ldots 3 N-6$, with $N$ being the number of atoms in the molecule). Assuming that the geometry of the molecule in a crystal is close 
to the free-molecule geometry, one can take the normal vibrational coordinates $Q_{\mu i n}^{k}$ of the free molecule as generalized internal coordinates. The difference in the geometric parameters causes deviations from the rotational Eckart conditions. Keeping the first-order angular terms only, one can express the Cartesian displacements $\xi_{p \alpha}^{k}$ of the atom $p$ in the molecule $k$ as [4]

$$
\xi_{p \alpha}^{k}=\sum_{\beta=1}^{3} \Lambda_{\alpha \beta}^{k}\left[t_{\beta}^{k}+\sum_{\rho=1}^{3} R_{\beta \rho}^{p} \theta_{\rho}^{k}\right]+\frac{1}{\sqrt{m_{p}}} \sum_{\mu=1}^{3 N-6} L_{p \alpha \mu}^{k} Q_{\mu i n}^{k} .
$$

Here $\alpha=x, y, z$ is the component index in the coordinate system of crystal, $\beta, \rho=u, v, w$ the component index in the principal inertia molecular axes coordinate system, $L_{p \alpha \mu}^{k}$ the eigenvector of the normal vibration of free molecule, $R^{p}$ the skew-symmetry matrix defined as $R^{p}=\left(\begin{array}{ccc}0 & w_{p} & -v_{p} \\ -w_{p} & 0 & u_{p} \\ v_{p} & -u_{p} & 0\end{array}\right), u_{p}, v_{p}$ and $w_{p}$ are the equilibrium atom coordinates in the molecular coordinate system, $\Lambda_{\alpha \beta}^{k}$ denotes the matrix of direction cosines of the principal inertia axes of the molecule $k$ and $m_{p}$ the mass of the atom.

For the Brillouin zone centre $(\mathbf{k}=0)$, the mass-weighted Cartesian and generalized coordinates are related to the phonon normal coordinates $Q_{j}$ [4]:

$$
\sqrt{m_{p}} \xi_{p \alpha}^{k}=\sum_{j} L_{p \alpha j}^{k} Q_{j}, \sqrt{M} t_{\beta}^{k}=\sum_{j} L_{\beta j}^{k} Q_{j}, \sqrt{I_{\rho}} \theta_{\rho}^{k}=\sum_{j} L_{\rho+3 j}^{k} Q_{j}, Q_{\mu i n}^{k}=\sum_{j} L_{\mu+6 j}^{k} Q_{j},
$$

where $L_{p a j}^{k}$ is the component of the eigenvector, $M$ the mass of the molecule and $I_{\rho}$ the principal moments of inertia. Using Eq. (1), the $L_{\beta j}^{k}$ components for the generalized coordinates have been obtained.

In the oriented gas approximation, the influence of intermolecular interactions on the optical properties of the molecules and the difference between the macroscopic and local fields are neglected. The Raman tensor of the unit cell in the oriented gas approximation for the normal mode $n$ can be expressed as [4]

$$
P_{n}=\sum_{k=1}^{Z} \frac{\partial \alpha^{(k)}}{\partial Q_{n}}
$$

where $\alpha^{(k)}$ is the molecular polarizability tensor of the molecule $k$ in motionless coordinate system of the crystal and $Z$ the number of molecules in the unit cell:

$$
\begin{gathered}
\frac{\partial \alpha^{(k)}}{\partial Q_{n}}=\sum_{\beta=1}^{3} \frac{\partial \alpha^{(k)}}{\partial t_{\beta}^{k}} \frac{\partial t_{\beta}^{k}}{\partial Q_{n}}+\sum_{\rho=1}^{3} \frac{\partial \alpha^{(k)}}{\partial \theta_{\rho}^{k}} \frac{\partial \theta_{\rho}^{k}}{\partial Q_{n}}+\sum_{\mu=1}^{3 N-6} \frac{\partial \alpha^{(k)}}{\partial Q_{\mu i n}^{k}} \frac{\partial Q_{\mu i n}^{k}}{\partial Q_{n}}, \\
\frac{\partial \alpha^{(k)}}{\partial t_{\beta}^{k}}=0, \frac{\partial \alpha^{(k)}}{\partial \theta_{\rho}^{k}}=\hat{\Lambda}^{k} \hat{C}_{\rho}\left(\hat{\Lambda}^{k}\right)^{T} .
\end{gathered}
$$

Here $\hat{\Lambda}^{k}$ is the matrix of direction cosines of the principal inertia axes $u, v, w$ of the molecule $k$ in the equilibrium position, 


$$
\begin{aligned}
& \hat{C}_{u}=\left(\begin{array}{ccc}
0 & -\alpha_{u w} & \alpha_{u v} \\
-\alpha_{u w} & -2 \alpha_{v w} & \alpha_{v v}-\alpha_{w w} \\
\alpha_{u v} & \alpha_{v v}-\alpha_{w w} & -2 \alpha_{v w}
\end{array}\right), \\
& \hat{C}_{v}=\left(\begin{array}{ccc}
2 \alpha_{u v} & \alpha_{v w} & \alpha_{w w}-\alpha_{u u} \\
\alpha_{v w} & 0 & -\alpha_{u v} \\
\alpha_{w w}-\alpha_{u u} & -\alpha_{u v} & -2 \alpha_{v w}
\end{array}\right), \\
& \hat{C}_{w}=\left(\begin{array}{ccc}
-2 \alpha_{u v} & \alpha_{u u}-\alpha_{v v} & -\alpha_{v w} \\
\alpha_{u u}-\alpha_{v v} & 2 \alpha_{u v} & \alpha_{u w} \\
-\alpha_{v w} & \alpha_{u w} & 0
\end{array}\right),
\end{aligned}
$$

and $\alpha_{\beta y}$ imply the elements of the molecular polarizability tensor in the coordinate system of the principal inertia axes.

The tensor $\partial \alpha^{(k)} / \partial Q_{\mu i n}^{k}$ is the Raman tensor for the free molecule, which can be expressed in terms of polarizability derivatives with respect to the real displacements [13]:

$$
\frac{\partial \alpha^{(k)}}{\partial Q_{\mu i n}^{k}}=\frac{1}{\sqrt{m_{\mu}}} \sum_{n=1}^{3 N} \phi_{\mu}^{n} \frac{\partial \alpha^{(k)}}{\partial \xi^{n}},
$$

where $m_{\mu}$ is the reduced mass of the normal mode, $\phi_{\mu}^{n}$ the normalized real displacements of the atoms in the Cartesian coordinates for the normal mode $\mu$ of isolated molecule, $\partial \alpha^{(k)} / \partial \xi^{n}$ the derivative of the polarizabilty tensor $\alpha^{(k)}$ of the molecule with respect to the real displacements $\xi^{n}$ of atoms, and $N$ the number of atoms in the molecule.

The intensity of the Raman lines can be evaluated according to the formula

$$
I_{k \gamma \beta}=\frac{\left(\omega_{e x c}-\omega_{k}\right)^{4}}{\omega_{k}}\left[n\left(\omega_{k}\right)+1\right]\left(R_{k \gamma \beta}\right)^{2},
$$

where $\omega_{\text {exc }}$ is the laser frequency, $n\left(\omega_{k}\right)+1=\left(1-\exp \left(-\frac{\hbar \omega_{k}}{k_{B} T}\right)\right)^{-1}$ the Bose occupation number, $\omega_{k}$ the frequency of the mode $k, k_{B}$ the Bolzmann constant, $\hbar$ the Planck constant, $T$ the temperature, and $R_{k \gamma \beta}$ the element of the Raman tensor for the mode $k$. Here the polarization of the scattered light is directed along the axis $\gamma$ and the incident radiation is polarized along $\beta$. Then the intensity has to been averaged as for polycrystalline samples [14].

We remind that the DFTB is an approximate quantum-chemical method based on the secondorder expansion of a Kohn-Sham total energy in the DFT with respect to the charge-density fluctuations. The unscaled frequencies of vibrations of the isolated HBO molecule calculated with the DFTB and DFT methods are compared in Table 1. The free HBO molecule is planar (the $\mathrm{C}_{\mathrm{S}}$ symmetry) and exhibits 47 vibrations with the symmetry $A^{\prime}$ and 22 vibrations with the symmetry A"; only 9 modes have the frequencies less than $350 \mathrm{~cm}^{-1}$. The next vibration is calculated to have the frequency $407 \mathrm{~cm}^{-1}$. Our results show that the unscaled frequency values obtained with the DFTB method agree well with the experimental parameters for the in-plane molecular vibrations in the region below $350 \mathrm{~cm}^{-1}$, although these frequencies are systematically (within $15 \mathrm{~cm}^{-1}$ ) lower than the values obtained using the DFT calculations. 
Table 1. Frequencies (in $\mathrm{cm}^{-1}$ ) and Raman activities (in arbitrary units) of the vibrations associated with isolated HBO molecule in the region below $350 \mathrm{~cm}^{-1}$.

\begin{tabular}{|c|c|c|c|c|c|c|}
\hline & \multicolumn{3}{|c|}{ Calculated parameter } & \multicolumn{2}{|c|}{ Description * } & Exp. $* *$ \\
\hline & $\begin{array}{c}\text { DFTB } \\
\text { frequency }\end{array}$ & $\begin{array}{c}\text { DFT } \\
\text { frequency }\end{array}$ & $\begin{array}{c}\text { DFT } \\
\text { Raman } \\
\text { activity }\end{array}$ & In-plane & Out-of-plane & Frequency \\
\hline 1 & 47 & 61 & 0.10 & & twist & \\
\hline 2 & 60 & 67 & 0.05 & & $\begin{array}{c}\text { out-of-plane } \\
\text { bending }\end{array}$ & \\
\hline 3 & 112 & 119 & 0.94 & $\begin{array}{c}\delta(\text { benzoxazole- } \\
\mathrm{CCO})+\delta \text { (benzoxazole } \\
-\mathrm{CCN})\end{array}$ & & 121 \\
\hline 4 & 151 & 163 & 2.60 & & $\begin{array}{c}\rho(\mathrm{phO}-10 \mathrm{~b})+ \\
\rho(\mathrm{ph}-10 \mathrm{a})\end{array}$ & \\
\hline 5 & 238 & 249 & 0.87 & & $\begin{array}{c}\rho(\text { phO-10b)+ } \\
\rho(\text { ph-10b) }\end{array}$ & \\
\hline 6 & 257 & 266 & 0.01 & & $\rho(\mathrm{ph}-10 \mathrm{~b})$ & \\
\hline 7 & 277 & 279 & 2.31 & $\begin{array}{c}\delta(\text { phO-CC })+\delta(\text { phO- } \\
\text { CCCring })+ \\
\delta(\text { benzoxazole- } \\
\mathrm{CCO})+\delta(\text { benzoxazole } \\
-\mathrm{CCN})\end{array}$ & & 280 \\
\hline 8 & 311 & 317 & 2.56 & $\delta(\mathrm{phO}-\mathrm{CCC})+\delta(\mathrm{ph}-9 \mathrm{~b})$ & & 310 \\
\hline 9 & 326 & 340 & 0.12 & & $\begin{array}{c}\rho(\text { ph-10a })^{+} \\
\rho(\text { phO-16b) }\end{array}$ & \\
\hline
\end{tabular}

* This description is approximate and uses a Varsanyi's notation [15] for the vibrations of aromatic compounds.

** According to the resonance Raman measurements in solution [3].

\section{Results and discussion}

As seen from Fig. 2, the unpolarized Raman spectrum for the HBO single crystals in the region $15-350 \mathrm{~cm}^{-1}$ consists of prominent narrow bands located at 33 and $40 \mathrm{~cm}^{-1}$, with a shoulder at $46 \mathrm{~cm}^{-1}$, five overlapping bands with approximately equal intensities in the region $50-130 \mathrm{~cm}^{-1}$, broad bands at 140,185, 195 and $262 \mathrm{~cm}^{-1}$, and weak narrow bands located at 300 and $316 \mathrm{~cm}^{-1}$. On the other hand, the DFTB phonon calculations predict 57 lattice vibrations (see Table 2) in the frequency region under study. Although these calculations employ no symmetry considerations, the eigenvectors obtained in this way satisfy approximately the symmetry relations. The symmetry types of the vibrations are defined according to the transformations of eigenvectors by the symmetry operations. The eigenvector components $L_{\beta j}^{k}$ corresponding to the generalized coordinates $\sqrt{M} t_{\alpha}^{k}, \sqrt{I_{\rho}} \theta_{\rho}^{k}$ and $Q_{\mu i n}^{k}$ are presented in Table 2 for the one molecule. The components for the translational and librational motions do not exceed 0.05 for the vibrations with the frequencies above $150 \mathrm{~cm}^{-1}$, so that the vibrations can be considered as entirely internal.

The results of comparison of the simulated and experimental Raman spectra (see Fig. 2) allow one to assign the bands observed at 185 and $195 \mathrm{~cm}^{-1}$ to the Davydov components $\mathrm{A}_{1}$ (the calculated frequency $\left.183 \mathrm{~cm}^{-1}\right)$ and $\mathrm{A}_{2}\left(185 \mathrm{~cm}^{-1}\right)$ of the out-of-plane molecular vibrations, which can be approximately described as $\rho($ phO-10b $)+\rho($ ph-10a) according to the Varsanyi's notation [15] (see mode 4 in Table 1). The frequencies calculated for the Davydov quartet are equal to 176, 183,185 and $189 \mathrm{~cm}^{-1}$, although the components 176 and $189 \mathrm{~cm}^{-1}$ are predicted to exhibit low 


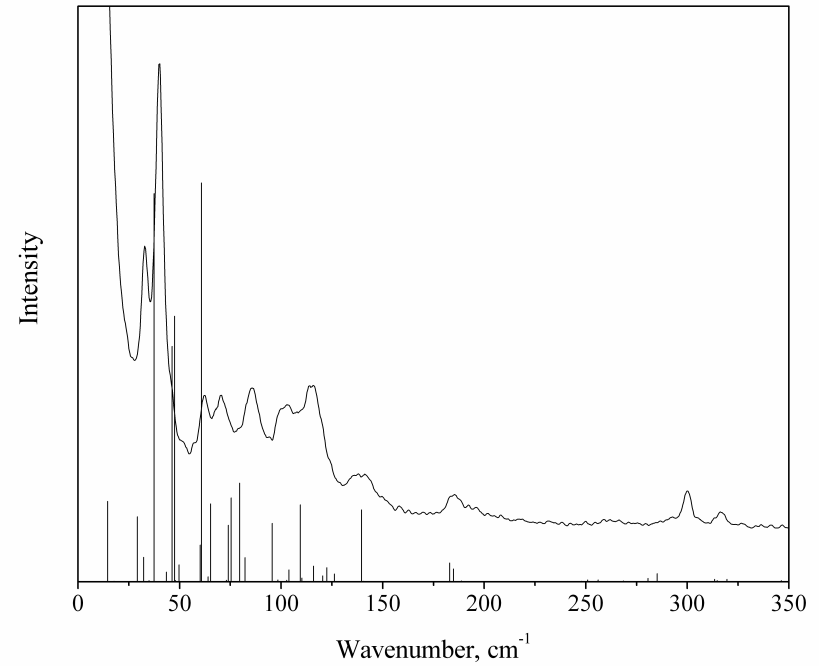

Fig. 2. Unpolarized Raman spectrum of HBO single crystals. The calculated frequencies and the corresponding relative peak intensities are represented as full vertical lines.

Table 2. Frequencies $\omega_{i}$ (in $\mathrm{cm}^{-1}$ ), symmetries $S$, components of the eigenvectors (corresponding to translations along the crystal axes $a, b$ and $c$, and rotations about the principal molecular axes $u, v$ and $w$ ), free-molecule vibrational normal modes (1-9), Raman intensities $I_{R}$ (in arbitrary units) of the phonon normal modes calculated for the HBO crystals, and frequencies of the Raman bands observed in experiments $\left(\omega_{\text {obs }}\right)$. Generalized coordinates with the components less than 0.05 are not shown.

\begin{tabular}{|c|c|c|c|c|c|c|c|c|c|c|}
\hline$N$ & 1 & 2 & 3 & 4 & 5 & 6 & 7 & 8 & 9 & 10 \\
\hline$\omega_{i}$ & 15 & 18 & 29 & 32 & 35 & 37 & 44 & 46 & 48 & 48 \\
\hline$S$ & $\mathrm{~B}_{2}$ & $\mathrm{~A}_{2}$ & $A_{1}$ & $\mathrm{~B}_{1}$ & $\mathrm{~A}_{2}$ & $A_{1}$ & $\mathrm{~A}_{2}$ & $\mathrm{~A}_{1}$ & $\mathrm{~B}_{1}$ & $\mathrm{~B}_{2}$ \\
\hline$a$ & -0.01 & -0.04 & 0.31 & 0.01 & 0.00 & -0.04 & -0.23 & 0.21 & 0.00 & -0.45 \\
\hline$b$ & 0.00 & 0.05 & -0.32 & 0.45 & -0.03 & -0.21 & 0.43 & 0.11 & 0.06 & 0.00 \\
\hline$c$ & 0.24 & 0.33 & 0.00 & 0.05 & -0.20 & 0.00 & -0.02 & 0.00 & -0.10 & -0.07 \\
\hline$u$ & 0.43 & -0.22 & -0.10 & -0.05 & 0.21 & 0.39 & 0.07 & 0.27 & 0.36 & 0.02 \\
\hline$v$ & -0.03 & 0.00 & -0.05 & 0.17 & 0.03 & 0.23 & 0.06 & -0.34 & 0.05 & -0.16 \\
\hline$w$ & 0.12 & -0.30 & 0.19 & -0.01 & -0.41 & -0.04 & 0.03 & -0.03 & -0.11 & -0.01 \\
\hline 1 & 0.05 & 0.05 & 0.08 & -0.07 & -0.09 & -0.05 & -0.04 & -0.12 & 0.30 & 0.09 \\
\hline 2 & 0.02 & 0.00 & -0.03 & 0.09 & -0.07 & -0.07 & -0.03 & 0.04 & 0.08 & -0.08 \\
\hline$I_{R}$ & 0.49 & 0.00 & 0.40 & 0.15 & 0.01 & 2.36 & 0.06 & 1.43 & 1.62 & 0.01 \\
\hline$\omega_{o b s}$ & & & & & & 33 & & 40 & 40 & \\
\hline$N$ & 11 & 12 & 13 & 14 & 15 & 16 & 17 & 18 & 19 & 20 \\
\hline$\omega_{i}$ & 50 & 60 & 61 & 64 & 65 & 73 & 74 & 75 & 80 & 82 \\
\hline$S$ & $\mathrm{~A}_{1}$ & $\mathrm{~B}_{2}$ & $\mathrm{~B}_{1}$ & $\mathrm{~A}_{2}$ & $\mathrm{~A}_{2}$ & $\mathrm{~B}_{1}$ & $\mathrm{~B}_{2}$ & $\mathrm{~A}_{1}$ & $\mathrm{~A}_{2}$ & $\mathrm{~B}_{1}$ \\
\hline$a$ & 0.12 & -0.11 & 0.00 & 0.14 & 0.24 & 0.00 & 0.14 & -0.29 & 0.25 & 0.00 \\
\hline$b$ & -0.11 & 0.00 & -0.02 & 0.03 & 0.20 & -0.14 & 0.00 & -0.25 & 0.09 & 0.01 \\
\hline$c$ & 0.00 & 0.36 & -0.21 & 0.29 & -0.12 & 0.15 & 0.00 & 0.00 & -0.02 & 0.41 \\
\hline$u$ & -0.13 & -0.20 & -0.29 & 0.34 & -0.11 & 0.07 & -0.06 & 0.02 & -0.15 & -0.06 \\
\hline$v$ & 0.02 & 0.04 & 0.11 & -0.06 & -0.28 & 0.44 & -0.45 & -0.29 & 0.32 & -0.11 \\
\hline$w$ & -0.45 & 0.07 & -0.30 & 0.05 & -0.04 & -0.02 & 0.16 & -0.06 & 0.01 & -0.18 \\
\hline 1 & -0.10 & -0.23 & 0.16 & -0.16 & -0.05 & -0.03 & -0.05 & 0.13 & -0.21 & 0.15 \\
\hline 2 & -0.10 & -0.07 & -0.07 & 0.06 & 0.20 & -0.12 & 0.02 & 0.00 & -0.08 & 0.00 \\
\hline 3 & 0.02 & -0.04 & -0.01 & 0.02 & -0.02 & 0.03 & -0.08 & 0.00 & 0.05 & -0.10 \\
\hline$I_{R}$ & 0.10 & 0.22 & 2.43 & 0.03 & 0.47 & 0.01 & 0.34 & 0.51 & 0.60 & 0.15 \\
\hline$\omega_{o b s}$ & 46 & & 62 & & 70 & & & 85 & 85 & \\
\hline
\end{tabular}


Low-frequency Raman

\begin{tabular}{|c|c|c|c|c|c|c|c|c|c|c|}
\hline$N$ & 21 & 22 & 23 & 24 & 25 & 26 & 27 & 28 & 29 & 30 \\
\hline$\omega_{i}$ & 96 & 98 & 103 & 104 & 109 & 109 & 110 & 116 & 121 & 123 \\
\hline$S$ & $\mathrm{~B}_{2}$ & $\mathrm{~A}_{2}$ & $\mathrm{~B}_{2}$ & $\mathrm{~A}_{1}$ & $\mathrm{~A}_{2}$ & $\mathrm{~B}_{2}$ & $\mathrm{~B}_{1}$ & $\mathrm{~A}_{1}$ & $\mathrm{~A}_{1}$ & $\mathrm{~A}_{2}$ \\
\hline$a$ & -0.05 & 0.19 & -0.10 & -0.10 & -0.11 & 0.02 & 0.00 & -0.03 & -0.04 & -0.04 \\
\hline$b$ & 0.01 & 0.10 & 0.00 & -0.03 & -0.06 & -0.01 & 0.03 & -0.09 & -0.10 & -0.04 \\
\hline$c$ & -0.23 & 0.00 & 0.01 & 0.00 & -0.01 & 0.03 & 0.03 & 0.00 & 0.00 & -0.02 \\
\hline$u$ & 0.09 & 0.13 & -0.03 & -0.09 & 0.00 & 0.06 & 0.10 & -0.07 & -0.02 & 0.02 \\
\hline$v$ & 0.06 & 0.16 & -0.01 & -0.07 & 0.16 & -0.13 & -0.08 & 0.02 & 0.01 & 0.10 \\
\hline$w$ & 0.29 & -0.03 & 0.00 & 0.14 & -0.03 & -0.27 & -0.25 & 0.00 & 0.01 & -0.02 \\
\hline 1 & -0.29 & 0.39 & -0.06 & -0.35 & -0.03 & -0.16 & -0.16 & -0.13 & -0.25 & -0.09 \\
\hline 2 & -0.05 & 0.04 & 0.48 & -0.28 & 0.41 & -0.03 & -0.09 & 0.28 & 0.26 & 0.12 \\
\hline 3 & 0.10 & -0.05 & 0.03 & 0.07 & 0.17 & 0.37 & 0.38 & 0.37 & -0.32 & -0.46 \\
\hline 4 & 0.03 & 0.08 & 0.09 & -0.03 & 0.10 & 0.01 & 0.05 & 0.09 & 0.03 & 0.02 \\
\hline$I_{R}$ & 0.36 & 0.01 & 0.01 & 0.07 & 0.00 & 0.47 & 0.02 & 0.10 & 0.04 & 0.09 \\
\hline$\omega_{o b s}$ & 102 & & & & & 115 & & & & \\
\hline$N$ & 31 & 32 & 33 & 34 & 35 & 36 & 37 & 38 & 39 & 40 \\
\hline$\omega_{i}$ & 126 & 140 & 141 & 176 & 183 & 185 & 189 & 248 & 251 & 256 \\
\hline$S$ & $\mathrm{~B}_{1}$ & $\mathrm{~B}_{2}$ & $\mathrm{~B}_{1}$ & $\mathrm{~B}_{1}$ & $\mathrm{~A}_{1}$ & $\mathrm{~A}_{2}$ & $\mathrm{~B}_{2}$ & $\mathrm{~B}_{1}$ & $\mathrm{~A}_{2}$ & $\mathrm{~A}_{1}$ \\
\hline$a$ & 0.00 & -0.02 & 0.00 & 0.00 & -0.03 & -0.01 & 0.02 & 0.00 & -0.01 & 0.01 \\
\hline$b$ & -0.12 & 0.00 & 0.05 & 0.04 & 0.00 & -0.01 & 0.00 & 0.00 & -0.01 & 0.00 \\
\hline$c$ & 0.04 & -0.08 & 0.06 & -0.01 & 0.00 & 0.01 & 0.00 & -0.01 & 0.00 & 0.00 \\
\hline$u$ & -0.09 & 0.15 & -0.14 & 0.02 & 0.01 & -0.01 & 0.00 & -0.01 & -0.01 & 0.01 \\
\hline$v$ & 0.07 & -0.01 & 0.00 & -0.03 & -0.04 & -0.10 & -0.06 & 0.02 & 0.03 & 0.00 \\
\hline$w$ & -0.01 & -0.26 & 0.25 & 0.05 & -0.02 & 0.02 & -0.03 & 0.02 & 0.00 & 0.02 \\
\hline 1 & 0.00 & -0.25 & 0.28 & 0.02 & 0.03 & -0.05 & 0.03 & 0.00 & -0.01 & -0.02 \\
\hline 2 & 0.43 & -0.01 & -0.08 & -0.14 & -0.08 & -0.08 & -0.08 & 0.02 & 0.02 & 0.00 \\
\hline 3 & 0.12 & -0.30 & 0.28 & -0.05 & -0.04 & -0.02 & -0.02 & 0.00 & -0.01 & 0.01 \\
\hline 4 & 0.16 & 0.00 & -0.05 & 0.47 & 0.49 & 0.48 & 0.49 & -0.04 & -0.07 & -0.02 \\
\hline 5 & 0.00 & -0.02 & 0.03 & -0.04 & 0.03 & -0.07 & -0.01 & -0.49 & -0.48 & 0.48 \\
\hline 6 & 0.00 & -0.04 & 0.05 & 0.01 & -0.01 & -0.03 & -0.02 & 0.06 & -0.03 & 0.10 \\
\hline 7 & 0.01 & 0.01 & -0.02 & 0.00 & 0.01 & -0.02 & -0.04 & 0.02 & 0.10 & -0.03 \\
\hline 8 & 0.01 & -0.01 & 0.01 & -0.01 & 0.00 & 0.00 & -0.01 & 0.05 & 0.04 & -0.05 \\
\hline 9 & -0.02 & 0.00 & 0.00 & 0.01 & 0.01 & 0.02 & 0.00 & -0.01 & 0.00 & 0.01 \\
\hline$I_{R}$ & 0.05 & 0.44 & 0.00 & 0.00 & 0.11 & 0.08 & 0.01 & 0.00 & 0.01 & 0.01 \\
\hline$\omega_{o b s}$ & & 140 & & & 185 & 195 & & & & 262 \\
\hline$N$ & 41 & 42 & 43 & 44 & 45 & 46 & 47 & 48 & 49 & 50 \\
\hline$\omega_{i}$ & 258 & 269 & 269 & 270 & 271 & 280 & 281 & 284 & 285 & 314 \\
\hline$S$ & $\mathrm{~B}_{2}$ & $\mathrm{~B}_{1}$ & $\mathrm{~A}_{2}$ & $\mathrm{~A}_{1}$ & $\mathrm{~B}_{2}$ & $\mathrm{~B}_{2}$ & $\mathrm{~A}_{2}$ & $\mathrm{~B}_{1}$ & $\mathrm{~A}_{1}$ & $\mathrm{~A}_{1}$ \\
\hline 5 & -0.48 & 0.09 & 0.06 & 0.03 & 0.10 & 0.06 & 0.09 & -0.01 & -0.04 & -0.05 \\
\hline 6 & 0.10 & 0.48 & 0.48 & -0.49 & -0.48 & -0.03 & -0.02 & 0.07 & 0.06 & -0.03 \\
\hline 7 & 0.06 & 0.02 & 0.07 & -0.02 & -0.06 & 0.49 & 0.49 & -0.49 & -0.49 & -0.03 \\
\hline 8 & 0.05 & -0.08 & -0.07 & 0.04 & 0.03 & -0.01 & -0.02 & 0.01 & 0.03 & -0.49 \\
\hline 9 & -0.04 & 0.01 & -0.02 & 0.01 & 0.04 & 0.00 & -0.01 & 0.02 & 0.02 & 0.02 \\
\hline$I_{R}$ & 0.00 & 0.00 & 0.00 & 0.00 & 0.00 & 0.00 & 0.02 & 0.00 & 0.05 & 0.02 \\
\hline$\omega_{o b s}$ & & & & & & & & & 300 & 316 \\
\hline$N$ & 51 & 52 & 53 & 54 & 55 & 56 & 57 & & & \\
\hline$\omega_{i}$ & 315 & 318 & 320 & 340 & 340 & 342 & 346 & & & \\
\hline$S$ & $\mathrm{~A}_{2}$ & $\mathrm{~B}_{2}$ & $\mathrm{~B}_{1}$ & $\mathrm{~A}_{2}$ & $\mathrm{~B}_{2}$ & $\mathrm{~B}_{1}$ & $\mathrm{~A}_{1}$ & & & \\
\hline 5 & -0.04 & -0.07 & -0.06 & -0.01 & -0.04 & 0.00 & -0.01 & & & \\
\hline 6 & -0.04 & -0.06 & -0.06 & -0.02 & 0.00 & -0.02 & 0.04 & & & \\
\hline 7 & -0.02 & -0.01 & -0.02 & -0.01 & 0.01 & -0.02 & 0.02 & & & \\
\hline 8 & -0.49 & -0.49 & -0.49 & -0.08 & 0.03 & -0.01 & 0.02 & & & \\
\hline 9 & 0.09 & 0.02 & 0.01 & -0.49 & 0.50 & -0.50 & 0.49 & & & \\
\hline$I_{R}$ & 0.01 & 0.00 & 0.01 & 0.00 & 0.00 & 0.00 & 0.01 & & & \\
\hline$\omega_{o b s}$ & & & & & & & & & & \\
\hline
\end{tabular}

Ukr. J. Phys. Opt. 2017, Volume 18, Issue 2 
intensity. The band observed at $262 \mathrm{~cm}^{-1}$ is assigned to the out-of-plane molecular vibration $\rho$ (ph$10 \mathrm{~b})$. The dominant component is determined to have the symmetry $\mathrm{A}_{1}\left(256 \mathrm{~cm}^{-1}\right)$. The band located at $300 \mathrm{~cm}^{-1}$ is due to the $\mathrm{A}_{1}$ component $\left(285 \mathrm{~cm}^{-1}\right)$. Finally, the band located at $316 \mathrm{~cm}^{-1}$ corresponds to the molecular bending vibration $\delta(\mathrm{phO}-\mathrm{CCC})+\delta(\mathrm{ph}-9 \mathrm{~b})$. The largest intensity is obtained for the $\mathrm{A}_{1}$ component $\left(314 \mathrm{~cm}^{-1}\right)$.

Table 3. Correlations among molecular symmetry, site symmetry and factor-group symmetry of intramolecular vibrations in the crystalline HBO.

\begin{tabular}{cc}
\hline Molecular symmetry $\left(\mathrm{C}_{\mathrm{s}}\right)$ & Site symmetry $\left(\mathrm{C}_{1}\right) \quad$ Factor group symmetry $\left(\mathrm{C}_{2 \mathrm{v}}\right)$ \\
\hline $\mathrm{A}^{\prime}-\mathrm{C}_{1} \cong \mathrm{A}_{1}$ \\
$\mathrm{~A}^{\prime \prime} \longrightarrow \mathrm{A}_{2}$ \\
$\mathrm{~B}_{1}$ \\
$\mathrm{~B}_{2}$ \\
\hline
\end{tabular}

The geometry of the HBO molecules calculated inside the crystal is close to planar; the dihedral angles formed by benzoxazole and phenolic moieties do not exceed $3^{\circ}$. Moreover, the isolated molecule is calculated to be more precisely planar. The molecules occupy general positions in the crystal cell, so that accurate separation of the translational and librational motions is not possible and the site symmetry remains $\mathrm{C}_{1}$. The dominant translational displacements are predicted for the vibrations with the calculated frequencies $29,32,44,48\left(B_{2}\right), 60$ and $82 \mathrm{~cm}^{-1}$, whereas the rotational displacements are predicted for the vibration frequencies $15,35,37,46,50$, 61,73 and $74 \mathrm{~cm}^{-1}$. The crystal mode located at $104 \mathrm{~cm}^{-1}$ corresponds mainly to the internal vibrations which can be described as a mixture of the out-of-plane molecular modes at 47 and $60 \mathrm{~cm}^{-1}$ (see Table 2). The mode at $48 \mathrm{~cm}^{-1}$ represents the internal vibration mixed with libration, while the modes located at 96 and $98 \mathrm{~cm}^{-1}$ are the internal vibration mixed with both libration and translation. The vibrations at $103\left(\mathrm{~B}_{2}\right), 109\left(\mathrm{~A}_{2}\right)$ and $126 \mathrm{~cm}^{-1}\left(\mathrm{~B}_{1}\right)$ are predominantly internal and correspond to the out-of-plane molecular vibration $60 \mathrm{~cm}^{-1}$. The seven modes lying in the region $109-141 \mathrm{~cm}^{-1}$ involve the internal vibration similar to the in-plane molecular mode $\delta$ (benzoxazole$\mathrm{CCO}$ ) $+\delta$ (benzoxazole-CCN) (the calculated frequency being equal to $112 \mathrm{~cm}^{-1}$ and the experimental one to $\left.121 \mathrm{~cm}^{-1}[3]\right)$. Three of them are predominantly internal $\left(116\left(\mathrm{~A}_{1}\right), 121\left(\mathrm{~A}_{1}\right)\right.$ and $\left.123 \mathrm{~cm}^{-1}\left(\mathrm{~A}_{2}\right)\right)$ and the remaining vibrations are mixed with librations. However, the modes 116 and $121 \mathrm{~cm}^{-1}$ are mixtures of the in-plane and out-of-plane deformations that occur owing to symmetry lowering down to $\mathrm{C}_{1}$ (see Table 3 ). The in-plane vibration modulates the distance between the $\mathrm{O}$ and $\mathrm{N}$ atoms. Finally, all the other modes lying in the region below $150 \mathrm{~cm}^{-1}$ represent mainly the mixed translation-librational external vibrations.

The frequencies of the most intense Raman bands obtained following from our calculations demonstrate a good agreement with those of the bands actually observed in the measured spectrum. For instance, the intense band found theoretically at $37 \mathrm{~cm}^{-1}$, which originates from the full-symmetry $\mathrm{A}_{1}$ librational vibration around the principal axes $u$ and $w$, is quite close to the narrow band observed at $33 \mathrm{~cm}^{-1}$. The strong narrow band observed at $40 \mathrm{~cm}^{-1}$ can be attributed to overlapping of the bands caused by the full-symmetry $\left(\mathrm{A}_{1}\right)$ librational vibration around the principal axes $u$ and $w$ (the calculated frequency being $46 \mathrm{~cm}^{-1}$ ) and the mixed mode $\mathrm{B}_{1}$ located at $48 \mathrm{~cm}^{-1}$. The shoulder at $46 \mathrm{~cm}^{-1}$ can be assigned to the full-symmetry $\left(\mathrm{A}_{1}\right)$ vibration $50 \mathrm{~cm}^{-1}$, which is predominantly libration around the long molecular axis $w$. The band at $62 \mathrm{~cm}^{-1}$ 
corresponds to the $\mathrm{B}_{1}$ libration $\left(61 \mathrm{~cm}^{-1}\right)$. The location at $70 \mathrm{~cm}^{-1}$ for one of the bands is close to $65 \mathrm{~cm}^{-1}$, as calculated for the translational-librational vibration $\mathrm{A}_{2}$. The wider band at $85 \mathrm{~cm}^{-1}$ can be attributed to the overlapped lines originating from the librational mode $\left(74 \mathrm{~cm}^{-1}\right)$ and translational-librational modes $\mathrm{A}_{1}$ and $\mathrm{A}_{2}\left(75\right.$ and $80 \mathrm{~cm}^{-1}$, respectively). The bands calculated as the mixed modes located at $96 \mathrm{~cm}^{-1}$ (out-of-plane twisting, translation along the $c$ axis and libration about the $w$ axis with the symmetry $\mathrm{B}_{2}$ ) and at 109 and $140 \mathrm{~cm}^{-1}$ (mixture of in-plane bend, out-of-plane twisting and libration about the axis $w$ with the symmetry $\mathrm{B}_{2}$ ) agree well with the experimental bands found at 102, 115 and $140 \mathrm{~cm}^{-1}$. In general, the simulated spectrum exhibits a qualitative rather than quantitative agreement with the observed one, thus predicting unambiguously only the frequencies of the most intense bands.

\section{Conclusion}

The interactions among the HBO molecules in the crystalline state lead to appearance of the lattice vibrations in the region $15-150 \mathrm{~cm}^{-1}$, which is typical for the organic molecular crystals. The lattice vibrations in the frequency region $15-95 \mathrm{~cm}^{-1}$ are mainly external, while a considerable contribution of intramolecular vibrations is found only for the twisting internal vibrations. In the region $95-150 \mathrm{~cm}^{-1}$, the contribution of internal degrees of freedom is more significant. The inplane molecular bending vibration changes the distance between the $\mathrm{O}$ and $\mathrm{N}$ atoms constituting the hydrogen-transfer site and becomes split and mixed with both the out-of-plane and external vibrations. The vibrations located above $150 \mathrm{~cm}^{-1}$ are entirely internal and retain similarity to the corresponding molecular vibrations; a considerable splitting is found for the out-of-plane vibration located at $185 \mathrm{~cm}^{-1}$.

The oriented gas model demonstrates that modulations of polarizability of the crystal originating from librations of the molecules, under the assumption of constant molecular polarizability, can be responsible for the intense bands observed in the spectrum. Finally, we are to note that the oriented gas model represents only a rough estimation of the relative intensities since it does not take into account the influence of intermolecular interactions on the polarizability of molecules.

\section{References}

1. Hsieh C-C, Ho M-L and Chou P-T, 2010. Organic dyes with excited-state transformations (Electron, charge, and proton transfers). In 'Advanced Fluorescence Reporters in Chemistry and Biology. I: Fundamentals and Molecular Design’, Ed. by Demchenko A P. Springer Ser. Fluoresc. 8: 225-266.

2. Park S, Kwon O-H, Kim S, Park S, Choi M-G, Cha M, Park S Y and Jang D-J, 2005. Imidazole-based excited-state intramolecular proton-transfer materials: Synthesis and amplified spontaneous emission from a large single crystal. J. Amer. Chem. Soc. 127: 1007010074.

3. Pfeiffer M, Lenz K, Lau A, Elsaesser T and Steinke T, 1997. Analysis of the vibrational spectra of heterocyclic aromatic molecules showing internal proton and deuterium transfer. J. Raman Spectrosc. 28: 61-72.

4. Zhizhin G N and Mukhtarov E. Optical spectra and lattice dynamics of molecular crystals. Elsevier: Amsterdam (1995).

5. Tong Y-P, 2005. 2-(2-Hydroxyphenyl)-1,3-benzoxazole. Acta Cryst. E. 61: o3076-o3078.

6. Syetov Y, 2013. Luminescence spectrum of 2-(2'-hydroxyphenyl)benzoxazole in the solid state. Ukr. J. Phys. Opt. 14: 1-5.

Ukr. J. Phys. Opt. 2017, Volume 18, Issue 2 
7. Syetov Y and Vdovin A, 2010. Infrared spectra of benzoxazoles exhibiting excited state proton transfer. Vibr. Spectrosc. 53: 146-150.

8. Aradi B, Hourahine B and Frauenheim Th, 2007. DFTB+, a sparse matrix-based implementation of the DFTB method. J. Phys. Chem. A. 111: 5678-5684.

9. Gaus M, Cui Q and Elstner M, 2011. DFTB3: Extension of the self-consistent-charge densityfunctional tight-binding method (SCC-DFTB). J. Chem. Theory Comput. 7: 931-948.

10.Rappe A K, Casewit C J, Colwell K S, Goddard III W A and Skiff W M, 1992. Uff, a full periodic table force field for molecular mechanics and molecular dynamics simulations. J. Amer. Chem. Soc. 114: 10024-10035.

11. Schmidt M W, Baldridge K K, Boatz J A, Elbert S T, Gordon M S, Jensen J H, Koseki S, Matsunaga N, Nguyen K A, Su S J, Windus T L, Dupuis M and Montgomery J A, 1993. General atomic and molecular electronic structure system. J. Comput. Chem. 14: 1347-1363.

12. Gordon M C and Schmidt M W. Advances in electronic structure theory: GAMESS a decade later. Chapter 41 in 'Theory and Applications of Computational Chemistry, the first forty years', Ed. by C E Dykstra, G Frenking, K S Kim and G E Scuseria. Amsterdam: Elsevier (2005). P. 1167-1189.

13.Le Ru E C and Etchegoin P G. Principles of surface-enhanced Raman spectroscopy. Elsevier: Amsterdam (2009).

14.Prosandeev S A, Waghmare U, Levin I and Maslar J, 2005. First-order Raman spectra of $\mathrm{AB}^{\prime}{ }_{1 / 2}$ $\mathrm{B}_{1 / 2} \mathrm{O}_{3}$ double perovskites. Phys. Rev. B. 71: 214307-9.

15.Varsanyi G and Szoke S. Vibrational spectra of benzene derivatives. Academic Press: New York-London (1969).

Syetov Y. 2017. Low-frequency Raman spectrum of crystalline 2-(2'-hydroxyphenyl)benzoxazole and density-functional based tight-binding phonon calculations. Ukr.J.Phys.Opt. 18: 67 - 76.

Анотація. Неполяризований спектр комбінаційного розсіяння світла кристалічного 2-(2'-гідроксифеніл) бензоксазолу в області $15-350 \mathrm{~cm}^{-1}$ порівняно з результатами розрахунку коливань кристалічної тратки за допомогою методу функціонала густини в наближенні сильного зв'язку та моделі орієнтованого газу. Смуги, що спостерігаються в діапазоні 25-95 $\mathrm{cm}^{-1}$, віднесено до коливань, які є переважно зовнішніми, а смуги з частотами, вищими за $150 \mathrm{~cm}^{-1}$, віднесено до внутрімніх коливань. Молекулярне площинне деформаційне коливання, що змінюе відстань між атомами кисню та азоту, на яких має місце перенесення протона, піддається розщепленню та змішуванню з позаплощинними $i$ зовнішніми коливаннями. Це коливання відповідає смугам у спектрі поблизу 115 i $140 \mathrm{~cm}^{-1}$. 